\title{
EXPERIÊNCIA DE ENSINO DO PAISAGISMO NA UNIVERSIDADE ITALIANA
}

\author{
AN EDUCATION EXPERIENCE EDUCATION IN THE ITALIAN UNIVERSITY
}

\author{
ALVES, Henrique Pessoa Pereira \\ Professor de Arquitetura da Paisagem - Facoltà di Architettura Civile del Politecnico di Milano - Facoltà di \\ Architettura dell'Università luav di Venezia. E-mail: henrique.pessoa@virgilio.it
}

\section{RESUMO}

Este trabalho apresenta um quadro do estado atual do ensino do paisagismo na ltália, a partir das novas diretrizes e impulsos criados pelo documento de declaração da Convenção Européia da Paisagem. Procura-se indicar a particularidade do caso italiano, através de exemplos concretos de cursos de paisagismo em diferentes âmbitos universitários. Procura-se também analisar a recepção na ltália - particularmente no que concerne a atividade didática - das novas questões do paisagismo em âmbito internacional: como os fenômenos relativamente recentes que interessam a vida urbana nas sociedades avançadas são abordados a partir da tradição italiana de realização de espaços não edificados. Mira-se, portanto, a um estudo comparado do ensino da paisagem, na sua acepção mais ampla, e nos vários campos de sua aplicação, partindo de exemplos concretos e de experiências didáticas pessoais (no meu caso, através do ensino em cursos de graduação em arquitetura, nas orientações a TGls e mestrados de paisagismo, na pós-graduação em agronomia, na organização de workshops internacionais na Toscana, etc.).

\section{Palavras-chave: Paisagismo, ensino universitário e para-universitário, Itália, convenção européia da paisagem.}

Nas últimas décadas, tem-se verificado, nas universidades italianas, um interesse crescente pelos temas relacionados ao paisagismo, nas suas diversas acepções e escalas de projeto. Inicialmente, as matérias que mais se aproximavam à temática tinham um caráter prevalentemente histórico e estético, e praticamente se limitavam ao estudo da "Arte do Jardim", como eram então identificadas. Naquele momento, um outro filão de estudo, semelhante este, era a história da paisagem agrícola italiana.

Uma mudança radical neste cenário começou a verificar-se com a criação da Escola de Especialização em Arquitetura da Paisagem, instituída pela Faculdade de Arquitetura da Universidade de Gênova em 1981. Esse curso de pós-graduação era a resposta dada à exigência, já então sentida, de formação de profissionais altamente qualificados que fossem capazes de atuar no campo do projeto e planificação da paisagem, profissionais que serão em seguida requeridos pela assim chamada Lei Galasso, de 1985, que impôs às regiões italianas a adoção de um Plano Paisagístico que regulasse e governasse as transformações dos seus territórios em geral. Em seguida, essa tendência ao estudo do paisagismo foi fortemente incrementada pela Convenção Européia da Paisagem, adotada no ano 2000 pelos membros do Conselho Europeu. Essa convenção evidencia o papel importante representado pela paisagem, e sua influência no ambiente e no contexto da vida cotidiana das populações, tanto nos espaços naturais e rurais, quanto nos espaços urbanos e periurbanos; e, enfim, no plano cultural, ecológico, social e econômico. Além do mais, esta convenção evidencia as qualidades, as diferenças, o valor natural e cultural das inúmeras paisagens e nota a sua gradual deterioração, causada pelos mais variados fatores. Um outro mérito dessa convenção foi o incentivo dado aos Estados membros para a realização de uma formação de nível elevado no setor do conhecimento e das intervenções na paisagem, através do incremento, no ensino universitário, das disciplinas que tratam dos valores ligados 
à paisagem e das questões relativas à sua tutela, à sua gestão e planificação e ao seu projeto. Dada a dimensão européia que foi assim dada à questão da paisagem, houve, também por parte da ltália, a necessidade da formação do "arquiteto da paisagem" com iguais competências às dos seus colegas europeus. Hoje em dia, o ensino do paisagismo nas universidades italianas está presente em diferentes faculdades e em diferentes percursos formativos - dos assim chamados "corsi di laurea", às "lauree specialistiche", aos diversos cursos de pós-graduação, aos doutorados. A diversificação destes percursos está, numa certa medida, relacionada às novas diretrizes universitárias para os países da comunidade européia, segundo, porém, uma especificidade do ensino do paisagismo na Itália. Por outro lado, a declaração da Convenção Européia da Paisagem condiciona conteúdos e direciona os novos impulsos que se formam no interior de uma tradição de projeto paisagístico em princípio bem consolidados no ambiente propriamente italiano. Esta confluência entre novas tendências européias de projeto de paisagem e elementos tradicionais em um território fortemente marcado pelo acúmulo e sobreposição de experiências antigas, torna o caso italiano de particular interesse na análise dos novos percursos do ensino do paisagismo. Procuraremos aqui indicar algumas características específicas deste "caso italiano", acentuando aspectos problemáticos e novas perspectivas, que podem interessar o campo do paisagismo no Brasil.

Podemos, antes de mais nada, indicar algumas das faculdades em que tradicionalmente se inserem os cursos de formação em paisagismo, ainda que sob diferentes enfoques e âmbitos de interesse: a Faculdade de Arquitetura da Universidade de Gênova, como vimos, foi a primeira na ltália a ativar um curso de pós-graduação em Arquitetura da Paisagem; também foi a primeira a ativar a graduação de primeiro nível (trienal) "Técnicas para a Arquitetura da Paisagem", seguida pela Universidade Mediterrânea de Reggio Calabria: "Arquitetura dos Jardins e Paisagismo". Várias outras faculdades ativaram cursos de graduação de primeiro nível com temas relacionados ao paisagismo: "Gestão do Verde Urbano e da Paisagem", na Universidade de Pisa; "Gestão Técnica da Paisagem", na Universidade de Perugia; "Paisagem, Parques e Jardins", na Universidade de Pádua; "Projeto e Gestão de Áreas Verdes, Parques e Jardins", na Universidade de Catânia; "Verde Ornamental e Tutela da Paisagem", na Universidade de Bolonha; "Ciências Humanas do Ambiente, do Território e da Paisagem", na Universidade de Milão, entre tantas outras. Note-se que, em seguida a uma reforma universitária atuada há alguns anos, a formação universitária se distingue em um percurso inicial, de três anos, a assim chamada "laurea triennale" ou de "primeiro nível", e um curso bienal de especialização, a assim chamada "laurea magistrale", "specialistica" ou de segundo nível. Neste segundo momento do percurso formativo, o estudante é levado a construir mais livremente o próprio percurso, no interior de disciplinas mais próximas ao seu interesse, o que tem um forte impacto na natureza das matérias do paisagismo. Várias universidades - e neste caso não somente as faculdades de arquitetura - aviaram cursos de especialização em temas relacionados à paisagem. Alguns exemplos: o curso "Architetura para a Paisagem", na Universidade IUAV de Veneza; "Projeto dos Jardins, Parques e Paisagem", na Universidade Politecnico de Turim; "Ciência e Projeto da Paisagem", na Universidade de Bolonha; "Arquitetura da Paisagem" na Universidade La Sapienza de Roma e na Universidade de Gênova, "Ecologia e Planificação da Paisagem" na Universidade de Palermo.

A minha experiência pessoal no ensino da arquitetura da paisagem me permite constatar, mais uma vez, o aumento cada vez maior do interesse pelo tema da paisagem, o que pudia constatar já no curso de graduação tradicional (com os clássicos cinco anos), e agora dentro de cursos de graduação do primeiro nível não diretamente relacionados com o paisagismo: "Projeto de Parques, de Jardins e da Paisagem" e Arquitetura da Paisagem".

Vários outros cursos de pós-graduação proliferam nas diversas faculdades e são financiados pela Comissão da Comunidade Européia. Uma atenção particular deve ser dedicada aos cursos para-universitários, organizados em colaboração com institutos de ensino privados, que põem 
em confronto alunos dos últimos anos de graduação em paisagismo, com estudantes recémformados na área, ou em áreas afins.

Uma experiência extremamente estimulante, aberta também a estudantes estrangeiros, foi idealizada e coordenada por mim durante alguns anos, na cidade de Radicondoli, próximo de Siena. Esta experiência se articulava em torno de um projeto de paisagismo, cujo tema envolvia questões difíceis, relacionadas com uma paisagem "clássica" italiana, na região toscana. Em laboratórios intensivos de três semanas, jovens provenientes de várias partes da Itália se confrontavam com colegas australianos, alemães, israelenses, canadenses, ingleses, húngaros, espanhóis, etc., em função de um projeto que devia dar conta de uma marcante presença tecnológica moderna no interior de uma paisagem sedimentada e historicamente bem definida. A diferente formação e experiência cultural dos participantes conduzia a respostas variadas e permitia afrontar, em um ambiente ideal, alguns dos principais desafios do paisagismo contemporâneo.

\section{A. Quadro resumo do ensino do paisagismo na ltália}

1 - Cursos de graduação em "Arquitetura da paisagem" ou temas relacionados - curso de "laurea" de primeiro nível (3 anos). Ativado tanto em diversas escolas de arquitetura quanto em outras faculdades.

2 - Especialização ("Laurea specialistica") em "Arquitetura da paisagem" ou temas relacionados (no âmbito do novo sistema de graduação: 3 anos básicos - laurea triennale) +2 anos de especialização (laurea specialistica, magistrale ou de segundo nível). Ativado em diversas escolas de arquitetura assim como em outras faculdades.

3 - Matérias oferecidas no programa da graduação de outros cursos da "laurea triennale". Ativado em quase todas as escolas de arquitetura e em algumas outras faculdades, mas, em geral, como matérias optativas.

4 - Cursos de pós-graduação. Ativados em algumas faculdades de arquitetura e agronomia e, eventualmente, em outras faculdades.

5 - Cursos para-universitários.

\section{B. Experiência didática pessoal}

- Progettazione dei parchi, dei giardini e del paesaggio, matéria optativa - Facoltà di Architettura Civile del Politecnico di Milano (3ำ ano do curso $3+2$ ).

- Architettura del paesaggio, matéria integrativa do Laboratório de Projeto Urbano Facoltà di Architettura Civile del Politecnico di Milano (3a ano do curso $3+2$ ).

- Architettura del paesaggio, matéria fundamental no laboratório integrado de projeto no curso de especialização em "Arquitetura para a paisagem", Università IUAV di Venezia (1ㅇano do curso de especialização): Laboratório integrado 1ำ ano: projeto da paisagem urbanismo projeto do edifício.

- Laboratorio di progettazione dell'architettura del paesaggio, curso de pós-graduação da Faculdade de Agronomia da Università degli Studi di Milano (curso aberto a agrônomos, arquitetos, engenheiros, engenheiros florestais, ambientalistas, humanistas).

- Teses de graduação na Faculdade de Arquitetura e na Faculdade de Agronomia.

- Cursos de formação profissionalizante (para-universitário).

- Workshop internacional Landscape Design (com apoio do Istituto Europeo di Design). 


\section{Experiência didática: um exemplo do programa de exercícios - Facoltà di Architettura Civile del Politecnico di Milano - cursos de graduação do primeiro nível: Scienze dell'Architettura e Architettura delle Costruzioni}

Trata-se de um curso optativo oferecido para o terceiro ano dos cursos de graduação trienais. Sendo um dos únicos cursos oferecidos que aborda os temas do projeto de paisagismo, e tratando-se de um curso semestral, de 60 horas/aula, houve a necessidade de concentrar e dosar a carga de informação, dividindo-a em três momentos distintos: uma apresentação teórica das novas questões do desenho da cidade contemporânea e das novas tendências internacionais do projeto de paisagismo no âmbito prevalentemente urbano e um paralelo com a cultura histórica do "projetar a paisagem"; um exercício propedêutico que introduz à "atitude" do projetista da paisagem; e um projeto final com um tema que diz respeito às questões do desenho das áreas não edificadas presentes nos interstícios do tecido urbano consolidado ou de fronteira. $O$ debate crítico sobre os significados que podem, ou devem, emergir do ato do projeto na criação de um desenho urbano aderente às necessidades e anseios de seus usuários, completa o processo de formação almejado. Exercício propedêutico:

- sensibilização ao tema da paisagem: - "O jardim de viagem" - introdução à leitura da paisagem com seus elementos básicos e estruturais.

- Genius loci.

- Instalação - "distúrbio" de um contexto dado com a introdução de novos atores, ou simples modificação na composição, ordem/lógica dos elementos compositivos presentes.

- Feed back - a paisagem é modificada e, por sua vez, modifica a instalação.

- Conclusão - experiência única no interior do programa dos cursos, no qual se é levado, a partir de uma leitura paisagística inicial, a intervir na paisagem, modificando-a até a realização material do projeto.

- Todas as etapas do projeto à realização são percorridas. Fatores como dificuldades técnicas, permissões especiais para intervir no espaço público, questões econômicas e tempo de realização têm que ser levadas em consideração.

- Exemplos de instalações - Projeto de paisagismo - áreas urbanas "de fronteira" e em grande transformação. O tecido "difuso". A interface entre área urbana e área agrícola. As áreas resíduas ainda presentes no tecido "consolidado".- $O$ problema das ex-áreas industriais. A ecologia urbana. A necessidade da criação de um "sistema" de verde. Os trabalhos são realizados em escalas muito variadas: do inquadramento geral na escala 1:50.000 / 1:25.000 até uma pequena escala de detalhe. A duração do curso não possibilita o desenvolvimento do projeto executivo. 